\title{
Application of a multiple criteria analysis for the selection of appropriate radical based processes in treatment of car wash wastewater
}

\author{
Elif DURNA, Nevim GENÇ ${ }^{\dagger}$ \\ Department of Environmental Engineering, Faculty of Engineering, Kocaeli Universty, 41000, Turkey
}

\begin{abstract}
In this study, the treatment of car wash wastewater was investigated by radical based hybrid/combined processes. Proposed processes, (Microwave $(\mathrm{MW})+$ persulfate $(\mathrm{PS})+$ Electrocoagulation $(\mathrm{EC})$ ), (ozone $\left.\left(\mathrm{O}_{3}\right)+\mathrm{PS}+\mathrm{EC}\right)$ and $\left(\mathrm{MW}+\mathrm{PS}+\mathrm{O}_{3}\right)$, were optimized with Taguchi orthogonal array technique for maximum COD removal. The COD removal under optimum conditions was obtained to be $84 \%, 64.9 \%$ and $61.4 \%$, for (MW + PS + EC), $\left(\mathrm{O}_{3}+\mathrm{PS}+\mathrm{EC}\right)$ and $\left(\mathrm{MW}+\mathrm{PS}+\mathrm{O}_{3}\right)$ processes, respectively. Operating costs for (MW + PS + EC), $\left(\mathrm{O}_{3}+\mathrm{PS}+\mathrm{EC}\right)$ and $(\mathrm{MW}$ $+\mathrm{PS}+\mathrm{O}_{3}$ ) processes have been calculated as $0.2614,0.1335$ and $0.2653 € / \mathrm{L}$ wastewater under optimum operating conditions. Pareto analysis showed that MW time and PS dose are very effective parameters but especially ozone related parameters have no significant effect on COD removal. Processes were evaluated with the PROMETHEE approach in terms of treatment efficiency, operating cost, sludge formation, and preferability criteria to determine the most suitable among the three alternative processes. As a result, the preference order of the processes for the treatment of car wash wastewater with radical based treatment processes was found as (MW + EC + PS) $>\left(M W+\mathrm{O}_{3}+\mathrm{PS}\right)>\left(\mathrm{O}_{3}+\mathrm{EC}+\mathrm{PS}\right)$.
\end{abstract}

Keywords: Car wash wastewater, Electrocoagulation, Microwave, Ozone, PROMETHEE

\section{Introduction}

The car wash industry is among the industries that consume large amounts of water and require a lot of chemical use [1]. Depending on the type of car wash and the size of the car, an average of 150-600 L of fresh-water is consumed per car wash [2, 3]. Reuse / recycling is an important issue due to the amount and complexity of wastewater in car wash stations [4].

Car wash wastewater may contain various pollutants such as detergents, phosphates, waxes, petroleum, and a wide range of hydrocarbons that make these effluents toxic to aquatic life [5]. Also, diesel organics such as oil and grease, carbon, asphalt, salts, ammonium compounds, heavy metals, acids and microorganisms in car wash effluents are among the pollutants of concern [6].

Increasing regulatory legislation and fresh water prices force the car wash industry to invest in process-integrated solutions [1]. Reuse is an important issue in car wash stations due to the amount and complexity of wastewater. [2]. Many European coun- tries have legislation for water recycling in car washing stations to reduce the volume of water consumed as well as reduce the pollutant release to the municipal treatment systems [7]. According to the Turkey Statistical Institute [8], the number of total cars is 23 million, but there is no statistical information about water consumption for car washes. However, restriction concerning discharge into the sewage system and receiving water body of treated car wash wastewater is present [8, 9]. Reuse/recycling of car wash wastewater for commercial car wash stations in Turkey was not legislated. Generally, in Turkey, car wash stations use artesian wells as the main water source. Wastewaters from these stations is passed through an oil-water separator or clarifier to remove oil and particulate matter before being discharged to municipal wastewater treatment plants. Efficient approaches are needed to eliminate hazardous pollution of wastewater and also to reuse after treatment. Due to the high reuse water quality for car wash and the limited space of car wash stations, high-impact treatment units with small space needs are required [4]. Criteria for car wash reclamation
This is an Open Access article distributed under the terms of the Creative Commons Attribution Non-Commercial License (http://creativecommons.org/licenses/by-nc/3.0/) which permits unrestricted non-commercial use, distribution, and reproduction in any medium, provided the original work is properly cited.

Copyright (C) 2021 Korean Society of Environmental Engineers
Received March 09, 2020 Accepted May 15, 2020

${ }^{\dagger}$ Corresponding author

Email: ngenc@ kocaeli.edu.com.tr

Tel: +90 (262) 3033200 Fax: +90 (262) 3033003

ORCID: 0000-0002-6185-1090 
systems should include general acceptance, aesthetic quality, microbiological risk and chemical content parameters [1]. Various treatment systems for reuse of car wash have been developed. Most of these systems are not sufficient for the quality of reuse water [10]. Some treatment methods used for the treatment of car wash wastewater include physicochemical processes [10-13], electro/chemical coagulation [2, 14, 15], chemical oxidation [4], electrochemical AOPs [7] and electrooxidation [16]. Although high efficiency is obtained with membrane processes, such processes require large areas and high costs. Furthermore, the oil-water emulsion contained in the car wash wastewater reduces membrane permeate flux [10]. Kiran et al. [17] found that the highest COD removal of $60 \%$ was achieved with the cellulose acetate membrane purification process of car wash water. Biological treatment methods do not seem to be attractive due to low biodegradability and bad nutrient balance of washing wastewater. However, Boluarte et al. [14] reported that after the process was acclimatized, the removal efficiency of COD in anoxic reactors and aerobic membrane bioreactor was about $99.2 \%$. In the car wash industry, most preferred processes for reclamation systems are physical-chemical treatment systems [2]. The removal efficiency of COD was obtained as $65.3 \%$ by adding poly-aluminum chloride coagulant to car wash wastewater [14]. Recent research has shown that electrochemical treatment techniques can be a good option for the reclamation of car wash wastewater $[2,7,16,18]$. In the study conducted by Sharma and Şimşek [19], it was found that the electrocoagulation (EC) process alone was significantly successful in removing suspended and colloidal contaminants. However, the maximum removal of dissolved organic pollutants was found to be relatively low.

AOPs are oxidation processes that produce radicals such as hydroxyl and sulfate in sufficient quantities to affect the chemical degradation of pollutants. Radical based processes have been widely used in treatment of various industrial and municipal wastewater. However, only a few studies have investigated these processes for car wash wastewater treatment. In these studies, the removal of COD was obtained as $71 \%, 75 \%$, and $82 \%$ by $\mathrm{H}_{2} \mathrm{O}_{2}$ [4], electrocoagulation and anodic oxidation integrated process [20] and electrooxidation process [21], respectively. Simple electrochemical or oxidation processes cannot significantly mineralize pollutants. Combining AOPs with other treatment processes, such as electrochemical technologies, is effective to achieve high pollutant removal efficiency at minimum cost [22]. Researchers have reported that the combination of electrochemical processes with ozone processes is a more efficient process because sludge and electrode passivation are lower than those achieved only by electrochemical processes [22-24]. Ozone-based AOPs are much more efficient than ozone process alone in removal of refractory compounds [25, 26]. Among the advanced treatment technologies, microwave (MW) technology has gained attention with its advantages such as short reaction time, high energy efficiency, fast heating and high reaction speed. Since MW's energy cannot break the chemical bonds of recalcitrant pollutants alone, it is common to use MW in combination with adsorbents, oxidants, catalysts, and AOPs [27, 28]. An activator is required to obtain $\mathrm{SO}_{4}{ }^{--}$radicals in PS oxidation. MW may act as an activator. The hybrid systems of PS and MW irradiation provide synergistic enhancement of the rate of organic contaminant degradation. MW irradiation increases the water temperature and accelerates PS activation and redox reactions.

The car wash industry is one of the industries with intensive water consumption and has a wide variety of chemical uses. Despite the efficiency shown in treatability with the radical-based processes of many industrial wastes, the applications of these processes for car wash wastewater containing complex soluble organic matter are rather scarce in the literature. Therefore, this study was focused on the evaluation of radical based combine/hybrid processes to treat car wash wastewater. In the studies on the treatment of car wash wastewater, each criterion that affects treatment efficiency was evaluated as alone. However, environmental, economic and social aspects should be evaluated together in the applicability of the treatment processes. The processes proposed in this study were evaluated with the PROMETHEE approach, which is one of the multi-criteria decision-making processes, and the most appropriate process was determined.

In this study, the radical based process combinations of (MW $+\mathrm{PS}+\mathrm{EC}),\left(\mathrm{O}_{3}+\mathrm{PS}+\mathrm{EC}\right)$ and $\left(\mathrm{MW}+\mathrm{PS}+\mathrm{O}_{3}\right)$ have been proposed for the destruction of refractory compounds in car wash wastewater containing highly dissolved complex organic matter. Each process has been optimized by Taguchi experimental design to determine the optimum operating parameters to maximize the COD removal. The effect of each operating parameter on the treatment efficiency was determined by Pareto analysis. Furthermore, using the fuzzy PROMETHEE method, the most suitable method among the proposed combinations for the treatment of car washing wastewater was determined.

\section{Material and Methods}

Wastewater: The real car wash wastewater was obtained from a car washing station with a daily capacity of from 40 to 50 cars in Istanbul, Turkey. In this station, different surfactants, rim cleaners and waxes are used during the washing process of the car. Therefore, the refractor organic matter content of wastewater is high. The COD value of the wastewater used is between $750-850 \mathrm{mg} / \mathrm{L}$ and the $\mathrm{pH}$ value is about 5-5.5.

Chemicals: Sodium sulfate $\left(\mathrm{Na}_{2} \mathrm{SO}_{4}\right)$ was purchased from Merck and used to obtain the specified current densities in EC processes. Sodium persulfate $\left(\mathrm{Na}_{2} \mathrm{~S}_{2} \mathrm{O}_{8}, 98 \%\right)$ was purchased from Merck and used as persulfate anion (PS) to create sulfate radicals. For pH adjustments, $\mathrm{NaOH}$ and $\mathrm{H}_{2} \mathrm{SO}_{4}$ were used which are also obtained from Merck.

Analysis: At each run, after samples were centrifuged using Hettich Universal 320 centrifuge device at 3,500 rpm, $15 \mathrm{~min}$ due to separate the solid particles from liquid, supernatant of treated samples were used for COD analysis. COD was analyzed by the closed reflux method according to the 'Standard Methods for the Examination of Water and Wastewater (APHA) [29].

Since sludge formation occurs in (MW + PS + EC) and EC + PS $+\mathrm{O}_{3}$ processes, these sludges are characterized by XRD and FTIR analysis. XRD (X-Ray Diffraction) and Fourier transform infrared (FTIR) analysis were carried out to confirm the nature as well as the bond stretching of the sludge respectively. X-Ray Diffractometer (XRD, RigakuSA-HF3) and Fourier transform infrared spectroscopy (FTIR, Perkin Elmer) were used for XRD 
and FTIR analysis, respectively. The sludge formed during EC was dried overnight in the air, then ground to a fine powder. Obtained powder was used for XRD and FTIR analysis. Powder XRD analysis was performed with $\mathrm{CuK} \alpha$ radiation source with a scanning speed of $1.0^{\circ} / \mathrm{min}$ at $40 \mathrm{kV}$ and $20 \mathrm{~mA}$. Samples were collected from $10^{\circ}$ to $80^{\circ}(2 \theta)$. The spectra of FTIR was obtained in the range of $4,000-650 \mathrm{~cm}^{-1}$.

The experimental devices used in the study are described in Supplementary Materials.

\subsection{Methodology}

In this study, (MW + PS + EC), $\left(\mathrm{O}_{3}+\mathrm{PS}+\mathrm{EC}\right)$ and (MW + PS $+\mathrm{O}_{3}$ ) processes were optimized by the Taguchi L8 experimental design to determine the operating conditions for the maximum COD removal of car wash wastewater. Schematic diagrams of combined / hybrid processes and levels of factors affecting COD removal are given in Fig. 1.

\subsection{Optimization and Decision Making}

The Taguchi methodology is widely used in experimental design studies and considered to be a more advantageous method than other methods since it requires fewer experiments and less cost. Taguchi recommends using the loss function to measure performance characteristics that deviate from the set value. Further, the value of the loss function becomes a signal-to-noise $(\mathrm{S} / \mathrm{N})$ ratio indicating the desired portion/unwanted portion. The optimal operating conditions are calculated from the $\mathrm{S} / \mathrm{N}$ ratio of the results obtained from studies designed with the Taguchi orthogonal array technique [30]. The S / N ratios are varied, usually, indicated with three types, i.e. smaller-the better, larger-the-better and nominal-the-better [31]

The preference of three optimized hybrid systems by Taguchi methodology was then ranked by the fuzzy PROMETHEE approach. For optimization Design Expert 10.0.4, for decision making Visual PROMETHEE Academic Edition software was used.

Multi-criteria decision making (MCDM) is used to score or rank a limited number of alternatives, taking into account the multiple criteria. PROMETHEE is an MCDM method developed by Brans et al. [32]. It is a very simple ranking method understanding and application compared to other MCDM methods. It is well adapted to problems with multiple or conflicting criteria of the finite set of alternatives [33].
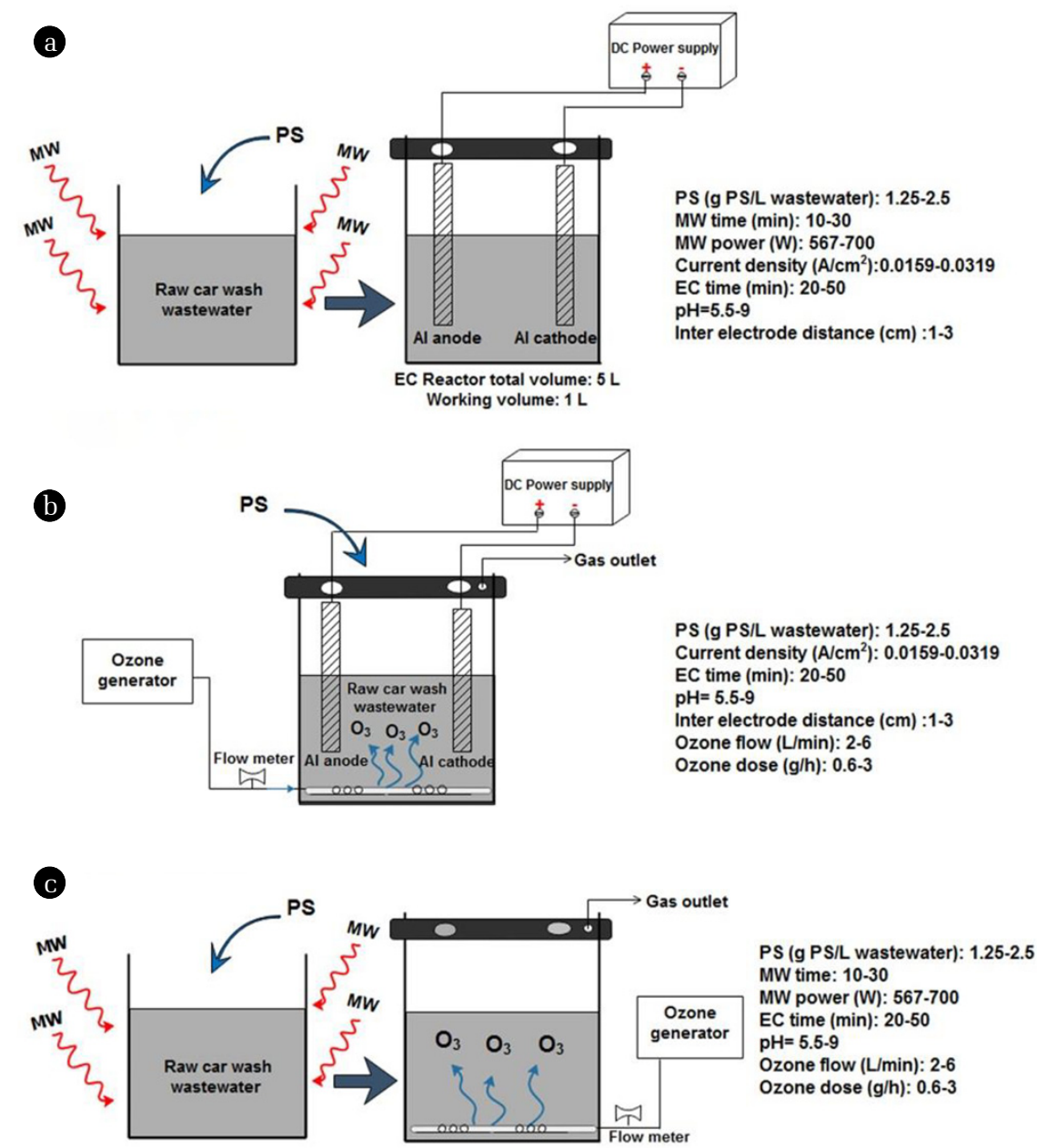

Fig. 1. Schematic diagrams of combined / hybrid processes. (a) $M W+P S+E C$, (b) $\mathrm{O}_{3}+P S+E C$, (c) $M W+P S+O_{3}$. 
When comparing the two alternatives considered a and $\mathrm{b}$ in terms of criteria, a P function is preferred. This function explains the difference between the two alternatives evaluated based on a particular criterion, within a degree of preference ranging from 0 to 1 . The general representation of this $\mathrm{P}$ function is expressed as in Eq. (1).

$$
P_{j}(a, b)=\left\{\begin{array}{ll}
0, & f(a) \leq f(b) \\
p[f(a)-f(b)], & f(a)>f(b)
\end{array}\right\}
$$

With the selected preference function, the alternatives are compared in pairs on the basis of the criterion. The basic steps of PROMETHEE are as follows [34-36].

Step 1: For each criterion, one of the 6 preference functions is selected. The preference functions are given in Table S1 in Supplementary Materials.

Step 2: Preference index for each alternative is determined by Eq. (2) by making binary comparisons of alternatives with the preference function determined by Step 1 .

$$
\pi(a, b)=\sum_{j=1}^{n} w_{j} \times P_{j}(a, b)
$$

where $\mathrm{w}_{\mathrm{j}}$ is the weight of the criterion and $\mathrm{n}$ is the number of evaluation factors.

Step 3: For each alternative, positive (Eq. (3)) and negative flows (Eq. (4)) are determined.

$$
\begin{aligned}
& \Phi^{+}(a)=\frac{1}{n-1} \sum_{b \in A} \pi(a, b) \\
& \Phi^{-}(a)=\frac{1}{n-1} \sum_{b \in A} \pi(b, a)
\end{aligned}
$$

Step 4: PROMETHEE I partial and PROMETHEE II net rankings are performed with the calculated positive and negative currents. The relationship between alternative a and alternative $\mathrm{b}$ is as follows [37].

$$
\begin{aligned}
& \text { is superior to } \mathrm{b}\left\{\begin{array}{l}
\Phi^{+}(a)>\Phi^{+}(b) \text { and } \Phi^{-}(a)<\Phi^{-}(b) \\
\Phi^{+}(a)>\Phi^{+}(b) \text { and } \Phi^{-}(a)=\Phi^{-}(b) \\
\Phi^{+}(a)=\Phi^{+}(b) \text { and } \Phi^{-}(a)<\Phi^{-}(b)
\end{array}\right\} \\
& \text { a is no different from } \mathrm{b}\left\{\begin{array}{l}
\Phi^{+}(a)>\Phi^{+}(b) \text { ve } \Phi^{-}(a)<\Phi^{-}(b) \\
\Phi^{+}(a)>\Phi^{+}(b) \text { ve } \Phi^{-}(a)=\Phi^{-}(b) \\
\Phi^{+}(a)=\Phi^{+}(b) \text { ve } \Phi^{-}(a)<\Phi^{-}(b)
\end{array}\right\}(6) \\
& \text { a can not be compared with } \mathrm{b}\left\{\begin{array}{l}
\Phi^{+}(a)>\Phi^{+}(b) \text { ve } \Phi^{-}(a)>\Phi^{-}(b) \\
\Phi^{+}(a)<\Phi^{+}(b) \text { ve } \Phi^{-}(a)<\Phi^{-}(b)
\end{array}\right\}(7)
\end{aligned}
$$

Despite its advantages, the PROMETHEE method has a disadvantage in terms of the uncertainty associated with situations that should be expressed in linguistic expressions, and the inputs are often based on the thoughts and experiences of decision-makers. In order to eliminate this uncertainty, Fuzzy PROMETHEE, which is an improved version of the PROMETHEE method with fuzzy numbers, has emerged. The method aims to obtain more sensitive and more specific results. Triangular fuzzy number equivalents, which adopt five linguistic variables proposed by Li [38] were used in the study (Table S2 in Supplementary Materials).

In this study, the linguistic expressions determined by the decision-makers were first converted into triangular fuzzy numbers, averaged and then defuzzyficated based on criteria. The defuzzification of a triangular fuzzy number $(\mathrm{a}, \mathrm{b}, \mathrm{c})$ is carried out according to Eq. (8) [39].

$$
D=\frac{a+7 b+c}{12}
$$

where $\mathrm{D}$ is the defuzzyficated value.

\section{Results and Discussion}

\subsection{Optimization Study}

The Taguchi L8 experimental design was used for optimization of operating conditions of the three proposed process configurations. The COD removal efficiency was used as the response parameter in the experimental design using two levels of seven factors. The levels of the factors used in the processes were determined by preliminary studies. In the Taguchi experiment design, it is desirable to obtain low, medium and high COD removal values, the levels of factors are selected to achieve a homogeneous distribution. For example, the original $\mathrm{pH}$ value of the wastewater used in the study is between 5-5.5, after the addition of PS, the $\mathrm{pH}$ of the water decreases therefore, the acidic $\mathrm{pH}$ level was not used in the experimental design. Selected $\mathrm{pH}$ levels provided wide range of COD removal efficiencies.

The Taguchi L8 experimental designs of three combined processes, resulting COD removal efficiencies and $\mathrm{S} / \mathrm{N}$ values are given in Table 1. The $\mathrm{S} / \mathrm{N}$ values are calculated according to the "higher is the better" condition for maximum COD removal efficiency.

The suitability of the models can be validated through the ANOVA. F and $\mathrm{P}$ values obtained from ANOVA analysis for all three procedures are given in Table S3 in Supplementary materials. The $\mathrm{F}$ value indicates the ratio of the mean of the squared deviations to the mean of square error, while the P-value, defined as the ratio of the sum of square of the variables to the total sum of square, shows the contribution of the variables to the response [23]. The high F values imply that the models are significant. Model parameters with a $\mathrm{P}$ value of less than 0.05 are considered to be significant.

In this study, optimization of 3 combined/hybrid systems was performed for maximum COD removal. The optimum conditions and the experimental results at these conditions for (MW + PS $+\mathrm{EC}),\left(\mathrm{O}_{3}+\mathrm{PS}+\mathrm{EC}\right)$ and $\left(\mathrm{MW}+\mathrm{PS}+\mathrm{O}_{3}\right)$ are given in Fig. 2 (a), (b), (c), respectively.

Combining the EC process with other treatment processes might improve treatment performance. Ozone can oxidize pollutants directly with the oxidation ozone molecule and/or indirectly by $\mathrm{OH}^{*}$ radical formation. In $\mathrm{O}_{3} / \mathrm{EC}$ combination, $\mathrm{Al}(\mathrm{OH})_{3}$ served as catalysts 
surface, adsorbents/co-precipitants in the wastewater. Ozone can decompose in the active metal regions on the surface of the catalysts. Dissolved ozone is adsorbed on the surface of the catalyst and then decomposes rapidly due to the presence of hydroxyl groups. Ozone in the gas phase can rapidly decompose to oxygen and a free $\mathrm{OH}^{*}$ radical on the surface of metal oxides, oxidizing organic compounds in solution or on the catalyst surface [40]. In the study carried out by Qi et al. [41], was shown that aluminum (hydroxyl) oxides such as $\gamma-\mathrm{Al}_{2} \mathrm{O}_{3}, \gamma-\mathrm{AlOOH}$ and $\alpha-\mathrm{Al}_{2} \mathrm{O}_{3}$ enhanced the rate of ozone decomposition. Higher density of surface hydroxyl groups of the aluminum oxide tested was favorable for the decay of ozone into hydroxyl radicals. $\mathrm{Na}_{2} \mathrm{~S}_{2} \mathrm{O}_{8}$, which dissociates in water to form $\mathrm{S}_{2} \mathrm{O}_{8}{ }^{2-}$, is a strong oxidant, however is kinetically slow to react with many organics [42]. By activation, $\mathrm{S}_{2} \mathrm{O}_{8}{ }^{2-}$ receives energy, the peroxide bond is split and two sulfate radicals are formed [43]. Microwave radiation is widely used in the activation of persulfate anion in $\mathrm{SO}_{4}^{-{ }^{-}}$radical based processes [27]. The $\mathrm{SO}_{4}^{-{ }^{-}}$radical formed according to the Eq. (9), has proved to be highly effective in removing pollutants.

$$
\mathrm{S}_{2} \mathrm{O}_{8}^{2-}+\text { energy imput } \rightarrow 2 \mathrm{SO}_{4}^{--}
$$

In $\mathrm{O}_{3} / \mathrm{PS}$ system, $\mathrm{S}_{2} \mathrm{O}_{8}{ }^{2-}$ reacts with ozone and the oxidation agent of organic materials such as $\mathrm{SO}_{4}{ }^{\bullet-}$ and $\mathrm{O}_{2}{ }^{\bullet-}$ as is produced [44-46].

$$
\begin{gathered}
\mathrm{O}_{3}+\mathrm{OH}^{-} \rightarrow \mathrm{HO}_{2}^{-}+\mathrm{O}_{2} \\
\mathrm{O}_{3}+\mathrm{HO}_{2}^{-} \rightarrow \mathrm{OH}_{2}^{\circ}+\mathrm{O}_{3}^{--} \\
\mathrm{O}_{3}^{\circ-}+\mathrm{H}_{2} \mathrm{O} \rightarrow \mathrm{OH}^{\bullet}+\mathrm{O}_{2}+\mathrm{OH}^{-} \\
\mathrm{S}_{2} \mathrm{O}_{8}^{2-}+\mathrm{OH}^{\bullet} \rightarrow \mathrm{HSO}_{4}^{--}+\mathrm{SO}_{4}^{--}+1 / 2 \mathrm{O}_{2} \\
2 \mathrm{~S}_{2} \mathrm{O}_{8}^{2-}+2 \mathrm{H}_{2} \mathrm{O} \stackrel{\mathrm{OH}^{-}}{\longrightarrow} 3 \mathrm{SO}_{4}^{2-}+\mathrm{SO}_{4}^{--}+\mathrm{O}_{2}^{--}+4 \mathrm{H}^{+}
\end{gathered}
$$

\begin{tabular}{|c|c|c|c|c|c|c|c|c|c|}
\hline Method & $\begin{array}{c}\text { A: } \\
\text { MW time } \\
\text { (min) }\end{array}$ & $\begin{array}{c}\text { B: } \\
\text { PS dose } \\
\text { (g/L) }\end{array}$ & $\begin{array}{c}\text { C: } \\
\text { Current density } \\
\left(\mathrm{A} / \mathrm{cm}^{2}\right)\end{array}$ & $\begin{array}{c}\text { D: } \\
\text { EC time } \\
\text { (min) }\end{array}$ & $\begin{array}{l}\text { E: } \\
\text { pH }\end{array}$ & $\begin{array}{c}\text { F: } \\
\text { MW power } \\
(W)\end{array}$ & $\begin{array}{c}\text { G: } \\
\text { Inter electrode } \\
\text { distance }(\mathrm{cm})\end{array}$ & $\begin{array}{c}\text { COD } \\
\text { removal } \\
(\%)\end{array}$ & $\begin{array}{l}\mathrm{S} / \mathrm{N} \\
\text { ratio }\end{array}$ \\
\hline \multirow{8}{*}{$\begin{array}{l}\text { (MW+ } \\
\text { PS+EC) }\end{array}$} & 10 & 1.25 & 0.0159 & 20 & 5.5 & 700 & 1 & 48.50 & 33.714 \\
\hline & 10 & 1.25 & 0.0159 & 50 & 9 & 567 & 3 & 52.00 & 34.320 \\
\hline & 10 & 2.5 & 0.0319 & 20 & 5.5 & 700 & 3 & 70.00 & 36.901 \\
\hline & 10 & 2.5 & 0.0319 & 50 & 9 & 700 & 1 & 68.00 & 36.650 \\
\hline & 30 & 1.25 & 0.0319 & 20 & 9 & 700 & 3 & 67.00 & 36.521 \\
\hline & 30 & 1.25 & 0.0319 & 50 & 5.5 & 567 & 1 & 75.00 & 37.501 \\
\hline & 30 & 2.5 & 0.0159 & 20 & 9 & 567 & 1 & 80.00 & 38.061 \\
\hline & 30 & 2.5 & 0.0159 & 50 & 5.5 & 700 & 3 & 70.00 & 36.901 \\
\hline \multirow{9}{*}{$\begin{array}{l}\left(\mathrm{O}_{3}+\right. \\
\mathrm{PS}+\mathrm{EC})\end{array}$} & $\begin{array}{c}\text { A: } \\
\text { PS dose } \\
\text { (g/L) }\end{array}$ & $\begin{array}{c}\text { B: } \\
\text { Current } \\
\text { density } \\
\left(\mathrm{A} / \mathbf{d m}^{2}\right)\end{array}$ & $\begin{array}{l}\text { C: } \\
\text { Time } \\
\text { (min) }\end{array}$ & $\begin{array}{l}\text { D: } \\
\text { pH }\end{array}$ & $\begin{array}{c}\text { E: } \\
\text { Inter electrode } \\
\text { distance }(\mathrm{cm})\end{array}$ & $\begin{array}{c}\text { F: } \\
\text { Ozone flow } \\
\text { (L/min) }\end{array}$ & $\begin{array}{c}\text { G: } \\
\text { Ozone dose } \\
\text { (g/h) }\end{array}$ & $\begin{array}{c}\text { COD } \\
\text { removal } \\
(\%)\end{array}$ & $\begin{array}{l}\mathrm{S} / \mathrm{N} \\
\text { ratio }\end{array}$ \\
\hline & 1.25 & 0.0159 & 20 & 5.5 & 1 & 2 & 0.6 & 45.45 & 33.1506 \\
\hline & 1.25 & 0.0159 & 20 & 9 & 3 & 6 & 3 & 54.38 & 34.7087 \\
\hline & 1.25 & 0.0319 & 50 & 5.5 & 1 & 6 & 3 & 55.10 & 34.8230 \\
\hline & 1.25 & 0.0319 & 50 & 9 & 3 & 2 & 0.6 & 56.10 & 34.9792 \\
\hline & 2.5 & 0.0159 & 50 & 5.5 & 3 & 2 & 3 & 51.72 & 34.2731 \\
\hline & 2.5 & 0.0159 & 50 & 9 & 1 & 6 & 0.6 & 55.17 & 34.8340 \\
\hline & 2.5 & 0.0319 & 20 & 5.5 & 3 & 6 & 0.6 & 50.00 & 33.9794 \\
\hline & 2.5 & 0.0319 & 20 & 9 & 1 & 2 & 3 & 53.24 & 34.5247 \\
\hline \multirow{9}{*}{$\begin{array}{l}(\mathrm{MW}+ \\
\left.\mathrm{PS}+\mathrm{O}_{3}\right)\end{array}$} & $\begin{array}{c}\text { A: } \\
\text { MW time } \\
\text { (min) }\end{array}$ & $\begin{array}{c}\text { B: } \\
\text { MW power } \\
(W)\end{array}$ & $\begin{array}{l}\text { C: } \\
\text { pH }\end{array}$ & $\begin{array}{c}\text { D: } \\
\text { PS dose } \\
(\mathrm{g} / \mathrm{L})\end{array}$ & $\begin{array}{c}\text { E: } \\
\text { Ozone time } \\
\text { (min) }\end{array}$ & $\begin{array}{c}\text { F: } \\
\text { Ozone flow } \\
\text { (L/min) }\end{array}$ & $\begin{array}{c}\text { G: } \\
\text { Ozone dose } \\
\text { (g/h) }\end{array}$ & $\begin{array}{c}\text { COD } \\
\text { removal } \\
(\%)\end{array}$ & $\begin{array}{l}\mathrm{S} / \mathrm{N} \\
\text { ratio }\end{array}$ \\
\hline & 30 & 567 & 9 & 2.5 & 20 & 5 & 0.6 & 21.05 & 26.4650 \\
\hline & 10 & 700 & 9 & 1.25 & 20 & 5 & 3 & 22.80 & 27.1586 \\
\hline & 30 & 700 & 5.5 & 1.25 & 50 & 5 & 0.6 & 19.29 & 25.7066 \\
\hline & 10 & 567 & 5.5 & 2.5 & 50 & 5 & 3 & 42.10 & 32.4856 \\
\hline & 30 & 700 & 5.5 & 2.5 & 20 & 3 & 3 & 38.59 & 31.7294 \\
\hline & 30 & 567 & 9 & 1.25 & 50 & 3 & 3 & 47.36 & 33.5082 \\
\hline & 10 & 700 & 9 & 2.5 & 50 & 3 & 0.6 & 43.00 & 32.6693 \\
\hline & 10 & 567 & 5.5 & 1.25 & 20 & 3 & 0.6 & 47.36 & 33.5082 \\
\hline
\end{tabular}

Table 1. Taguchi L8 Experimental Designs and COD Removal Results of Proposed Processes 

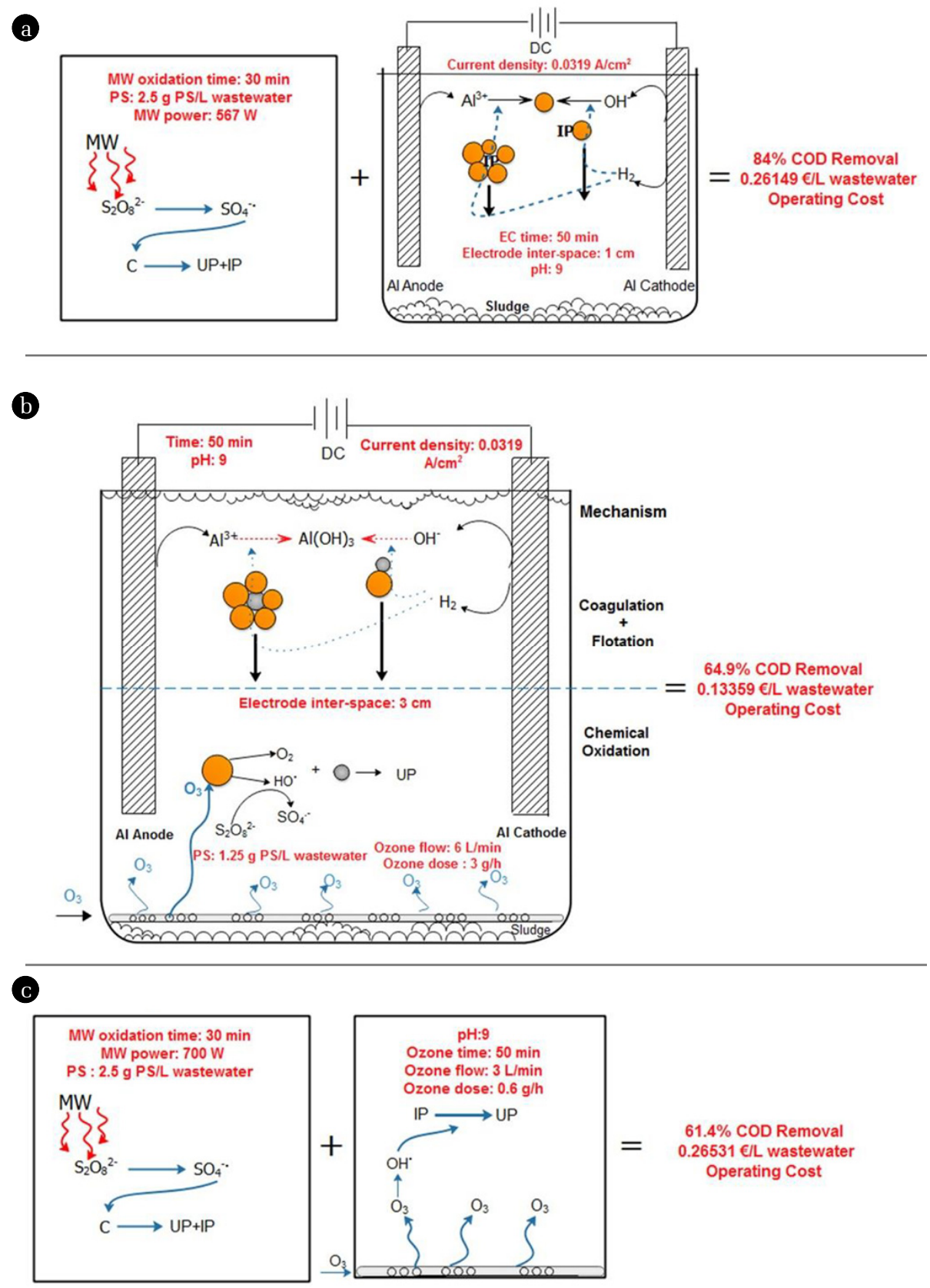

Fig. 2. The mechanisms and optimization results of the proposed processes (the optimum experimental conditions and results obtained from the optimum experiments are expressed in red text color, $\mathrm{C}$ : Contaminant, UP: Ultimate product, $\mathrm{IP}=\mathrm{Intermediate}$ product, $\mathrm{O}: \mathrm{Al}(\mathrm{OH})_{3}$, $\mathrm{Al}(\mathrm{OH})_{2}{ }^{+}, \mathrm{Al}(\mathrm{OH})^{++} \ldots, \mathrm{O}$ : Contaminant). (a) $\mathrm{MW}+\mathrm{PS}+\mathrm{EC}$ process, (b) $\mathrm{O}_{3}+\mathrm{PS}+\mathrm{EC}$ process, (c) $\mathrm{MW}+\mathrm{PS}+\mathrm{O}_{3}$ process.

In this study, 84, 64.9 and $61.4 \%$ COD removals were obtained for the $(\mathrm{MW}+\mathrm{PS}+\mathrm{EC}),\left(\mathrm{O}_{3}+\mathrm{PS}+\mathrm{EC}\right)$ and $(\mathrm{MW}+\mathrm{PS}+$ $\mathrm{O}_{3}$ ) processes at optimum conditions determined by Taguchi experimental design, respectively. In the study conducted by Orescanin et al. [47], 76.3\% COD removal was achieved in the treatment of boat pressure washing wastewater containing approximately $215 \mathrm{mg} / \mathrm{L}$ COD by EC / ozonation process. Rubí-Juárez et al. [21] reported that they achieved 70\% COD removal by electro- coagulation of car wash water containing $488 \mathrm{mg} / \mathrm{L}$ COD.

The COD removal efficiencies obtained in this study seem to be low compared to electrocoagulation-based treatments of car wash wastewater in the literature. However, the wastewater used in this study was taken from the station where there is a large amount of polisher and detergent usage with the high average COD content of $800 \mathrm{mg} / \mathrm{L}$. In addition to treatment efficiency, economic and social aspects of processes should also be taken into consideration 
in the evaluation of environmental processes. For this purpose, the processes were evaluated with PROMETHEE, which is one of the multi-criteria decision making processes, considering all the criteria.

Energy and chemical consumption were taken into account to calculate the operating cost of each process. The unit energy cost in the energy consumption of the ozone generator, DC power supply, and MW oven is assumed to be $0.074 € / \mathrm{kWh}$. The unit costs of $\mathrm{NaOH}$ and $\mathrm{H}_{2} \mathrm{SO}_{4}$ used in $\mathrm{pH}$ adjustment, $\mathrm{Na}_{2} \mathrm{~S}_{2} \mathrm{O}_{8}$ used as oxidation agent and $\mathrm{Na}_{2} \mathrm{SO}_{4}$ used to increase the current density were considered as $0.0131 € / \mathrm{g}, 0.8 € / \mathrm{mL}, 0.072 € / \mathrm{g}, 0.0474 € / \mathrm{g}$, respectively. The cost of consumption of $\mathrm{Al}$ electrodes was calculated according to Gengeç et al. [48] and found to be $0.00368 € / L$ wastewater for $0.0319 \mathrm{~A} / \mathrm{cm}^{2}$. Operating costs for the (MW + PS + EC), $\left(\mathrm{O}_{3}+\right.$ $\mathrm{PS}+\mathrm{EC})$ and $\left(\mathrm{MW}+\mathrm{PS}+\mathrm{O}_{3}\right.$ ) processes were calculated as $0.2614,0.1335$ and $0.2653 € / \mathrm{L}$ wastewater under optimum operating conditions. It can be said that the operating cost of the processes combined with MW oxidation is approximately twice the cost of MW free processes.

In addition, Pareto analysis was performed in order to determine the effects of variables on COD removal efficiency of each combined system designed in Taguchi experimental design. Pareto analysis is a useful method of determining effects in order of magnitude and displaying the 5\% significance threshold (t-value limit) and an additional threshold (Bonferroni limit) corrected for multiple tests. The $t$ values of the bars represent the square root of the $\mathrm{F}$ values on the ANOVA. The coefficients that are the $\mathrm{t}$-value of the effect on the Bonferroni line are strictly defined as significant coefficients, and the coefficients with the t-value of the effect between the Bonferroni line and the t-limit are defined as likely to be significant, and the coefficients below the t-limit line are determined statistically insignificant [49, 50].

Fig. 3 shows the Pareto analysis of the Taguchi experimental design of the (MW + PS + EC) (a), $\left(\mathrm{O}_{3}+\mathrm{PS}+\mathrm{EC}\right)(\mathrm{b})$ and (MW $+\mathrm{PS}+\mathrm{O}_{3}$ ) (c) processes, respectively. The importance levels of the parameters in combined/hybrid operations were evaluated according to the "absolutely significant potential to be significant" order. Since the synergistic interactions of the parameters are possible, evaluating the effect of each parameter on the response alone would not be the correct approach. The effect of each parameter on COD removal was determined by taking into account all these interactions with Pareto analysis.

The most significant parameters in the ( $\mathrm{MW}+\mathrm{PS}+\mathrm{EC})$ process were MW time and PS dose, while current density and MW power were found to be potentially significant parameters and the inter-electrode distance, $\mathrm{pH}$, and EC time parameters were found to be insignificant. In the $\left(\mathrm{O}_{3}+\mathrm{PS}+\mathrm{EC}\right)$ process, $\mathrm{pH}$ and retention time parameters were found to be potentially significant, while other parameters were found to be insignificant. In the (MW + PS $+\mathrm{O}_{3}$ ) process, the MW time parameter was found to be potentially significant, while the other parameters were not significant. In the electrocoagulation process, inter-electrode distance parameter is considered as an effective parameter. However, in this study, this parameter was ineffective because other parameters in processes containing EC were more effective. The PS dose and MW oxidation time have a significant effect in the combined processes where the MW pretreatment step is applied. This shows that the oxidation
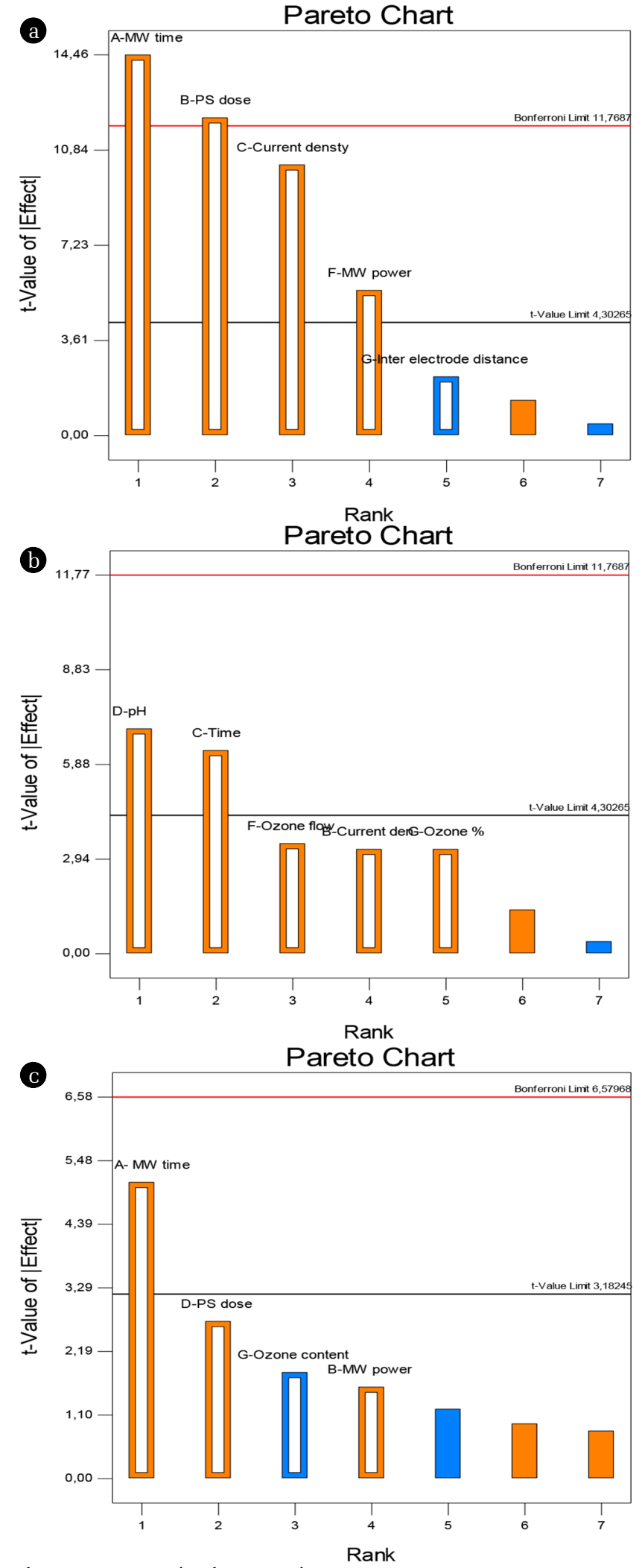

Fig. 3. Pareto graph of proposed processes (a) $(M W+P S+E C)$ process (b) $\left(\mathrm{O}_{3}+\mathrm{PS}+\mathrm{EC}\right)$ and (c) $\left(\mathrm{MW}+\mathrm{PS}+\mathrm{O}_{3}\right)$. 
mechanism of $\mathrm{SO}_{4}^{-\bullet}$ is essential (predominant) in COD removal. In the ozone assisted EC process, the factors characterizing the ozonation were found to be ineffective in COD removal.

\subsection{Characterization of The Sludge}

The qualitative and quantitative properties of sludge are important for their disposal. Sludge production depends on the characteristics of raw wastewater solids and the matter that is destabilized by coagulation and flocculation, as well as current density and resistance [51]. XRD analysis was performed to reveal the information about the crystallographic structure of the sludge. XRD spectra of the (MW + PS + EC) and $\left(\mathrm{O}_{3}+\mathrm{PS}+\mathrm{EC}\right)$ process sludges were shown in Fig. 4 (a) and (b), respectively. Broad peaks of
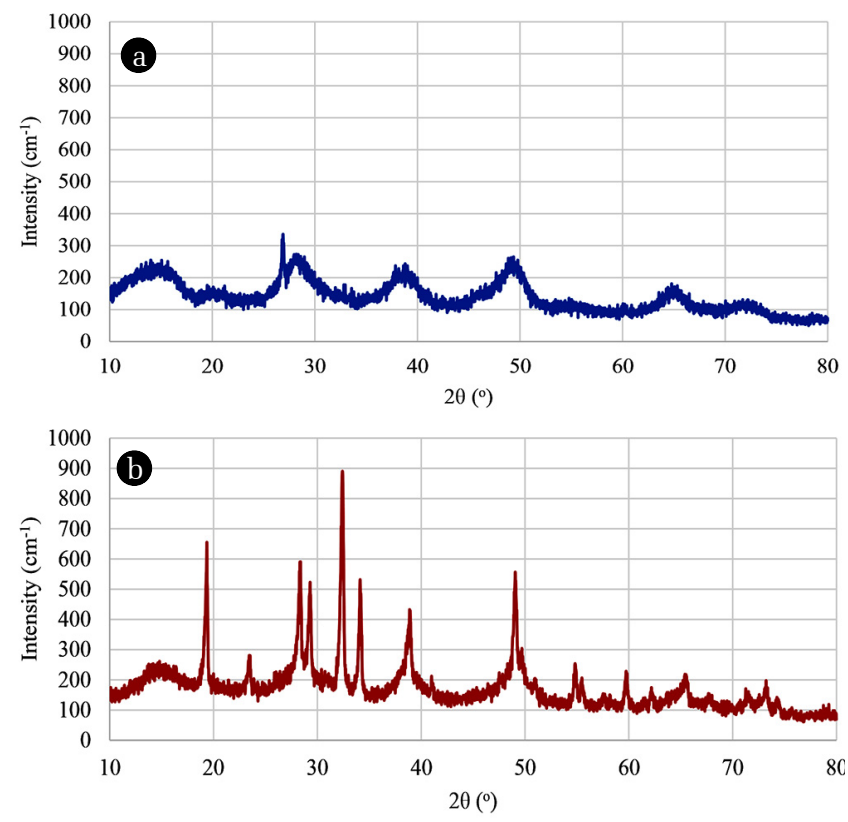

Fig. 4. XRD analysis of the sludges from (a) $(M W+P S+E C)$ and (b) $\left(\mathrm{O}_{3}+\mathrm{PS}+\mathrm{EC}\right)$ processes. alumina and diaspore (Al-O-OH) in the sludge were detected by $\mathrm{XRD}$. The XRD spectrum of the sludge generated from (MW + PS + EC) process showed broad and diffuse peaks which are amorphous or poorly crystalline structure [51]. The sludge generated from $\left(\mathrm{O}_{3}+\mathrm{PS}+\mathrm{EC}\right)$ was in the form of high crystallinity and a low amorphous phase.

FTIR analysis of sludge was used to determine the nature of the functional groups existing on its surface. FTIR spectra of the sludge were shown in Fig. 5. FTIR spectra indicated stretching vibrations at $3,351 \mathrm{~cm}^{-1}$ and $3,356 \mathrm{~cm}^{-1}$ bands attributed to $-\mathrm{OH}$ presence. The band at $2,901 \mathrm{~cm}^{-1}$ referred to the presence of $\mathrm{C}$ $=\mathrm{H}$. FTIR spectrum shows Al-O-H bending at a vibration range of 1,000-880 $\mathrm{cm}^{-1}$. Hydroxyl bending and $\mathrm{HO}-\mathrm{H}_{2} \mathrm{O}$ bending vibration, or overtones of hydroxyl bending are around 1,572-1,813 $\mathrm{cm}^{-1}$ [51]. The presence of the peaks at 730-733 in the sludge confirms the presence of carbonate [52]. The strong peak around $1,100 \mathrm{~cm}^{-1}$ is attributed to sulfate [53]. These bands indicate that the sludge produced by the $\mathrm{Al}$ electrode mostly contains hydroxides and oxyhydroxides [2].

\subsection{Decision Making Study}

In this study, the PROMETHEE decision-making method was used to rank the three proposed processes. The criteria to rank the processes for car wash wastewater management were determined as the operating cost of the process, removal efficiency, secondary waste generation, and preferability by car owners. For the criterion of removal efficiency, experimental COD removals obtained under optimum conditions were taken into consideration. For the cost criterion, operating costs under the optimized conditions of the three processes were also calculated. The values of the two other criteria, secondary waste generation and the criteria for preferability by vehicle owners, were obtained from the data expressed linguistically by 4 decision-makers. Thus, while the process cost and treatment efficiency criteria were used directly in numeric while the secondary waste generation and the preferred by car owners criterias were used by converting linguistic expressions into fuzzy numbers. The linguistical data obtained from 4 decision-makers was first

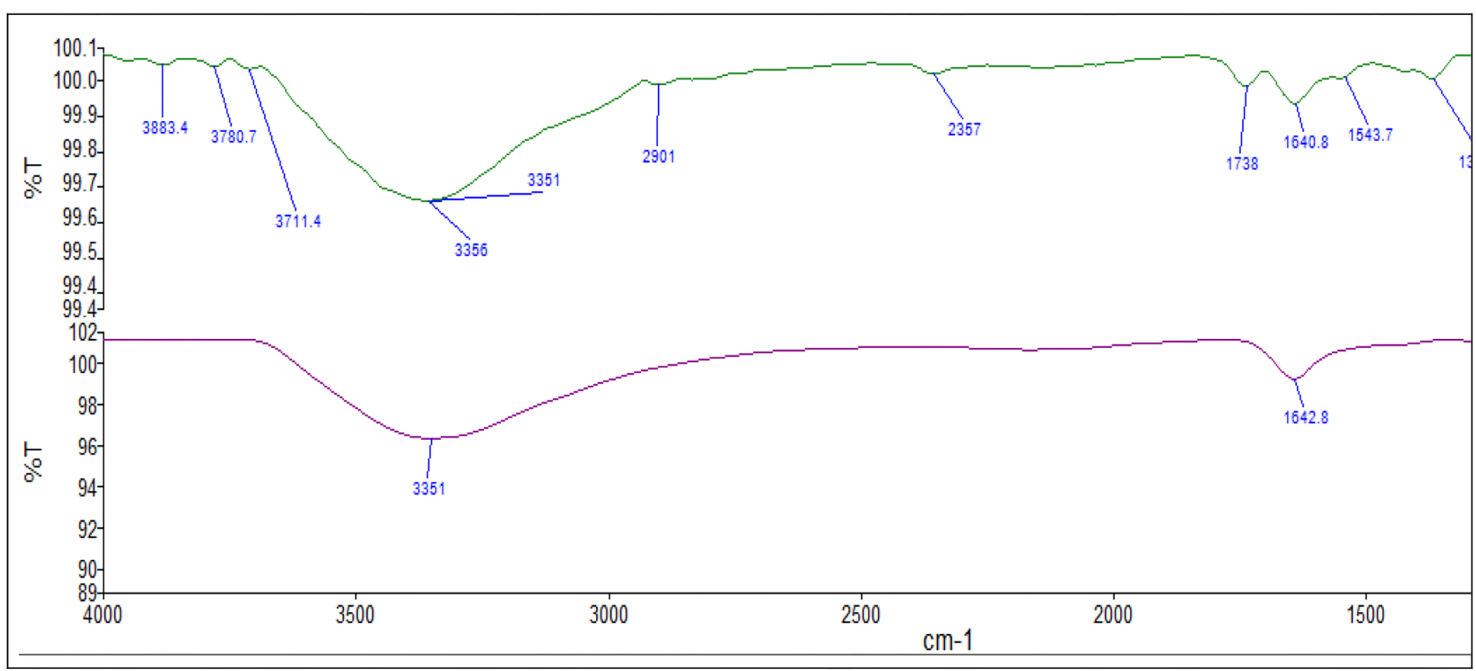

Fig. 5. FTIR analysis of the sludges from (MW+PS+EC) (green line) and $\left(\mathrm{O}_{3}+\mathrm{PS}+\mathrm{EC}\right)$ processes (purple line). 


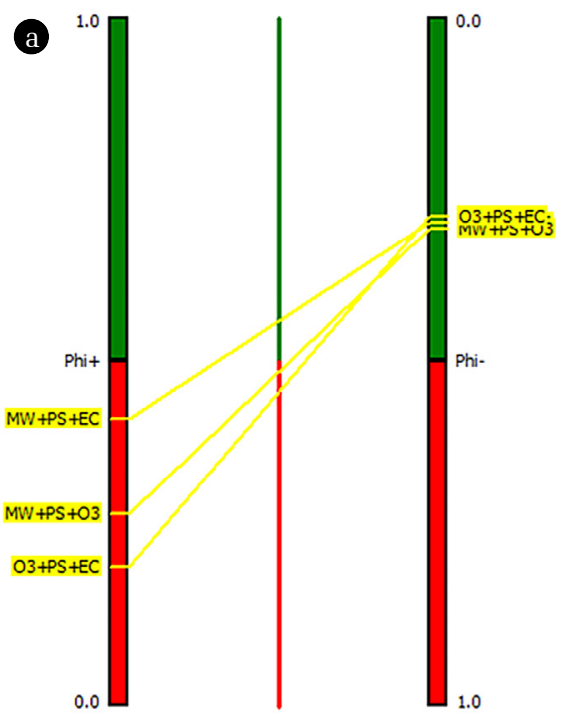

Fig. 6. (a) PROMETHEE I ranking, (b) PROMETHEE II ranking.

converted into fuzzy numbers, averaged and defuzzyficated as in the Eq. (8) and used numerically. These operations, which are used in the numerical expression of two linguistic criteria, are shown in Table S4(a) in Supplementary Materials. The final values used for the PROMETHEE ranking is shown in Table S4(b) Supplementary Materials. When selecting the most suitable method with PROMETHEE, linear preference function was used for cost and treatment efficiency criteria while the $\mathrm{V}$-shape preference function was used for secondary waste generation and car owners preference criteria. The weighting of treatment efficiency, operating cost, secondary waste generation and preferability criteria by vehicle owners, which are used to determine the appropriate method among alternative treatment methods, are accepted as 3, 1, 1, 1, respectively. Since each alternative method is intended for the reuse of car wash wastewater, such weighting is performed. Although there are no quality criteria for reuse of treated car wash water in Turkey, in this study, treatment efficiency was the determining factor in the selection of the alternative method.

When performing PROMETHEE I partial ranking, positive and negative currents are calculated between +1 and -1 for each alternative. Positive currents indicate the superiority of one alternative over others. While negative currents show how much one alternative is suppressed by other alternatives. The smaller the negative current value of an alternative, the more preferable it is. In PROMETHEE II, a clearer sequence is obtained with the net currents generated by the difference between positive and negative currents [54]. PROMETHEE I and II rankings are given in Fig. 6. In the positive currents shown in Fig. 6 (a), it is seen that the (MW + PS + EC) process is more preferable because it takes values near to 1 , whereas in the negative currents the $\left(\mathrm{O}_{3}+\mathrm{PS}+\mathrm{EC}\right)$ process is more preferable than other alternatives since it is near to zero. As shown in Fig. 6 (b), the PROMETHEE II net ranking of preferred alternatives was found to be $(\mathrm{MW}+\mathrm{PS}+\mathrm{EC})>\left(\mathrm{MW}+\mathrm{PS}+\mathrm{O}_{3}\right)>$ $\left(\mathrm{O}_{3}+\mathrm{PS}+\mathrm{EC}\right)$.

GAIA plane is the representation of PROMETHEE results as

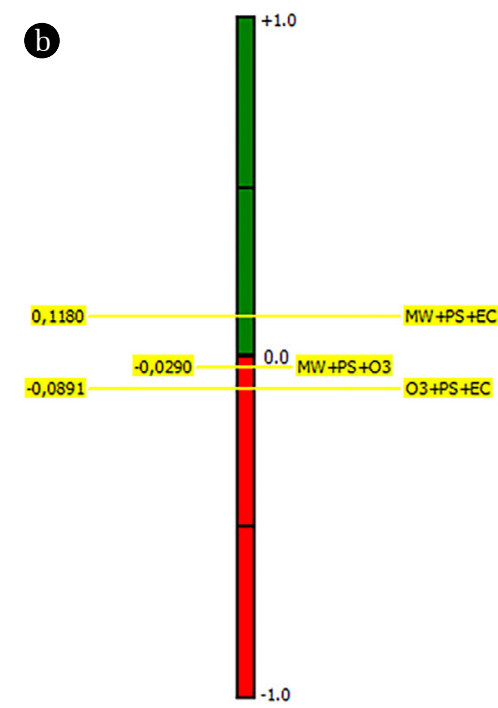

an extension of a visual and interactive procedure. The decision axis indicated by the red vector on the GAIA plane indicates the most preferred alternatives. Alternatives near to this line are acceptable. Furthermore, alternatives close to a criterion specify alternatives that should be preferred primarily for that criterion [54]. In this study, the GAIA plane is shown in Fig. 7. In the GAIA plane, the decision axis appears to be on the (MW + PS + EC) alternative side. Since the reuse of treated water is the primary objective when weighting the criteria in the study, the criteria given higher weighting were determinative in the ranking of alternatives. Since decision axis is close to treatment efficiency, it can be said that that criteria is effective in order to preference

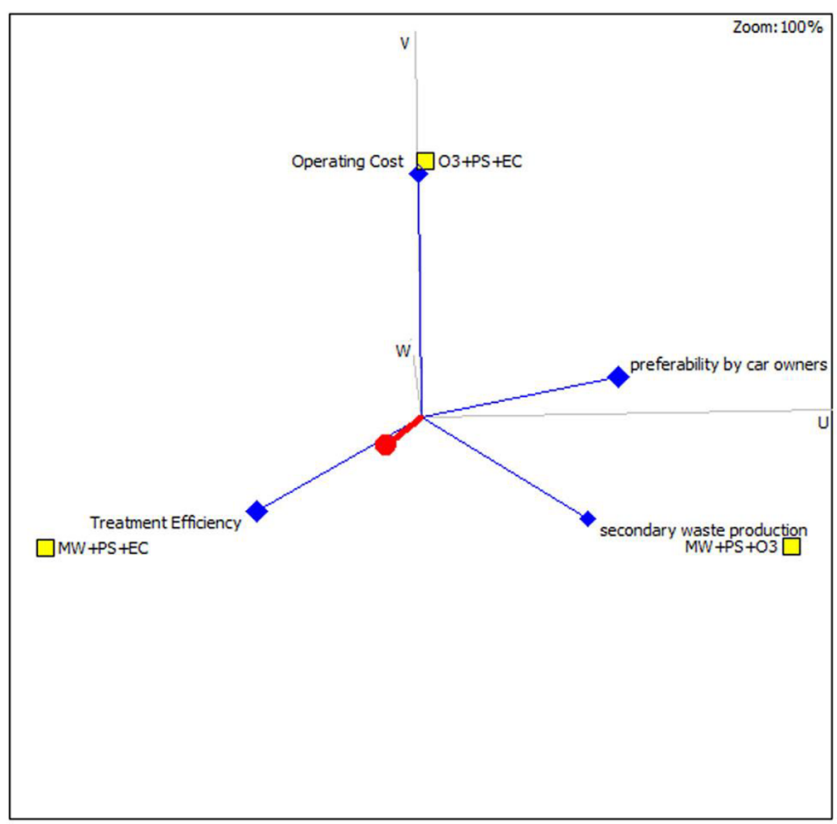

Fig. 7. GAIA visual analysis. 
of alternatives. The (MW + PS $+\mathrm{O}_{3}$ ) process has been particularly preferable in terms of secondary waste generation criteria. Likewise, $\left(\mathrm{O}_{3}+\mathrm{PS}+\mathrm{EC}\right)$ process is the preferred alternative in terms of operating cost criteria.

\section{Conclusions}

High water consumption in the car wash industry forces car washers to reuse treated water. On the other hand, since the wastewater from these industries contains very different complex and soluble structure, conventional treatment methods are inadequate and advanced treatment methods attracting attention. In this study, the treatment of car wash wastewater with radical based (MW + PS + EC), $\left(\mathrm{O}_{3}+\right.$ PS + EC) and (MW + PS + $\left.\mathrm{O}_{3}\right)$ combined/hybrid processes was examined. The results obtained are presented below;

- The operating conditions to ensure maximum COD removal of the evaluated processes have been optimized with Taguchi experimental design. COD removal under optimum conditions was found to be $84 \%, 64.9 \%$ and $61.4 \%$, for (MW + PS + EC), $\left(\mathrm{O}_{3}\right.$ $+\mathrm{PS}+\mathrm{EC})$ and $\left(\mathrm{MW}+\mathrm{PS}+\mathrm{O}_{3}\right)$, respectively. Operating costs for the $(\mathrm{MW}+\mathrm{PS}+\mathrm{EC}),\left(\mathrm{O}_{3}+\mathrm{PS}+\mathrm{EC}\right)$ and $(\mathrm{MW}+\mathrm{PS}+$ $\mathrm{O}_{3}$ ) processes were calculated as $0.2614,0.1335$ and $0.2653 € / \mathrm{L}$ wastewater under optimum operating conditions. The energy consuming units in the proposed processes were MW furnace, DC power supply and ozone generator. Energy consumption of (MW $+\mathrm{PS}+\mathrm{EC}),\left(\mathrm{O}_{3}+\mathrm{PS}+\mathrm{EC}\right)$ and $\left(\mathrm{MW}+\mathrm{PS}+\mathrm{O}_{3}\right)$ processes under optimum conditions was found to be 1.02, 0.84 and 0.459 kWh, respectively.

- By Pareto analysis, which determined the effect of each parameter on COD removal, it was determined that MW time had a significant effect in the processes of (MW + PS + EC and MW + PS $+\mathrm{O}_{3}$ ) where MW was used. It has been observed that the effect of PS can be considered important in processes where PS is activated with MW radiation. However, in processes where ozone is used (MW + PS $+\mathrm{O}_{3}$ and $\mathrm{O}_{3}+\mathrm{PS}+\mathrm{EC}$ ), the effect of ozone-related parameters on COD removal is negligible.

- The preference of the processes has been evaluated with the fuzzy PROMETHEE method by taking into account treatment efficiency, operating cost, sludge formation, and preferability criteria. The PROMETHEE II net ranking of alternatives was found to be $(\mathrm{MW}+\mathrm{PS}+\mathrm{EC})>\left(\mathrm{MW}+\mathrm{PS}+\mathrm{O}_{3}\right)>\left(\mathrm{O}_{3}+\mathrm{PS}+\mathrm{EC}\right)$. Also, in the GAIA plane, the decision axis appears to be on the MW $+\mathrm{PS}+\mathrm{EC}$ alternative side. The $\left(\mathrm{MW}+\mathrm{PS}+\mathrm{O}_{3}\right.$ ) process has been particularly preferable in terms of secondary waste generation criteria. Likewise, $\left(\mathrm{O}_{3}+\mathrm{PS}+\mathrm{EC}\right)$ process is the preferred alternative in terms of operating cost criteria.

\section{Acknowledgment}

Authors thank the Kocaeli University Scientific Research Projects coordination, BAP for their financial support to the national project (no: 2018/137). Authors also thank to Teknik Plastik company (Turkey) for their technical support.

\section{Author Contributions}

N.G. (Professor) and E.D. (Ph.D. Student) both contributed to both writing the manuscript and conducting experiments.

\section{References}

1. Zaneti R, Etchepare R, Rubio J. More environmentally friendly vehicle washes: water reclamation. J. Clean Prod. 2012;37: 115-124.

2. Gönder ZB, Balcıoğlu G, Vergili I, Kaya Y. Electrochemical treatment of carwash wastewater using $\mathrm{Fe}$ and $\mathrm{Al}$ electrode: Techno-economic analysis and sludge characterization. J. Environ. Manage. 2017;200:380-390.

3. Pinto ACS, de Barros Grossi L, de Melo RAC, et al. Carwash wastewater treatment by micro and ultrafiltration membranes: effects of geometry, pore size, pressure difference and feed flow rate in transport properties. J. Water Proc. Eng. 2017;17:143-148.

4. Bhatti ZA, Mahmood Q, Raja IA, Malik AH, Khan MS, Wu D. Chemical oxidation of carwash industry wastewater as an effort to decrease water pollution. Phys. Chem. Earth Parts $A / B / C$. 2011;36:465-469.

5. Qamar Z, Khan S, Khan A, Aamir M, Nawab J, Waqas, M. Appraisement, source apportionment and health risk of polycyclic aromatic hydrocarbons (PAHs) in vehicle-wash wastewater. Pakistan. Sci. Total Environ. 2017;605-606:106-113.

6. Tekere M, Sibanda T, Maphangwa KW. An assessment of the physicochemical properties and toxicity potential of carwash effluents from professional carwash outlets in Gauteng Province. South Africa. Environ. Sci. Pollut. Res. 2016;23:11876-84.

7. Ganiyu SO, Vieira dos Santos E, Tossi de Araújo Costa EC, Martínez-Huitle C.A. Electrochemical advanced oxidation processes (EAOPs) as alternative treatment techniques for carwash wastewater reclamation. Chemosphere 2018;211:998-1006.

8. Turkish Statistical Institute [Internet]. c2019 [cited March 1 2020]. Available from: https://biruni.tuik.gov.tr/medas/?locale $=$ tr.

9. Water Pollution Control Regulation of Turkey, published in the Official Gazette on Dec. 31, 2004 (No. 25687).

10. Hamada T, Miyazaki Y. Reuse of carwash water with a cellulose acetate ultrafiltration membrane aided by flocculation and activated carbon treatments. Desalination 2004;169:257-267.

11. Al-Odwani A, Ahmed M, Bou-Hamad S. Carwash water reclamation in Kuwait. Desalination 2007;206:17-28.

12. Boussu K, Kindts C, Vandecasteele C, Van der Bruggen B. Applicability of nanofiltration in the carwash industry. Sep. Purif. Technol. 2007;54:139-146.

13. Lau WJ, Ismail AF, Firdaus S. Car wash industry in Malaysia: Treatment of car wash effluent using ultrafiltration and nanofiltration membranes. Sep. Purif. Technol. 2013;104:26-31.

14. Rodriguez Boluarte IA, Andersen M, Pramanik BK, Chang CY, Bagshaw S, Farago L, Jegatheesan V, Shu L. Reuse of car wash wastewater by chemical coagulation and membrane bioreactor treatment processes. Int. Biodeterior. Biodegrad. 2016;113:44-48.

15. Mohammadi M], Takdastan A, Jorfi S, et al. Electrocoagulation 
process to chemical and biological oxygen demand treatment from carwash grey water in Ahvaz megacity. Iran. Data Brief. 2017;11:634-639.

16. Panizza M, Cerisola G. Applicability of electrochemical methods to carwash wastewaters for reuse. Part 1: Anodic oxidation with diamond and lead dioxide anodes. J. Electroanal. Chem. 2010;638:28-32.

17. Kiran SA, Arthanareeswaran G, Thuyavan YL, Ismail AF, Influence of bentonite in polymer membranes for effective treatment of car wash effluent to protect the ecosystem. Ecotoxicol. Environ. Saf. 2015;121:186-192.

18. El-Ashtoukhy ESZ, Amin NK, Fouad Y. Treatment of real wastewater produced from Mobil car wash station using electrocoagulation technique. Environ. Monit. Assess. 2015;187:628.

19. Sharma S, Simsek H. Treatment of canola-oil refinery effluent using electrochemical methods: A comparison between combined electrocoagulation + electrooxidation and electrochemical peroxidation methods. Chemosphere 2019;221: 630-639.

20. Panizza M, Cerisola G. Applicability of electrochemical methods to carwash wastewaters for reuse. Part 2: Electrocoagulation and anodic oxidation integrated process. J. Electroanal. Chem. 2010;638:236-240.

21. Rubí-Juárez H, Barrera-Díaz C, Linares-Hernández I, Fall C, Bilyeu B. A combined electrocoagulation-electrooxidation process for carwash wastewater reclamation. Int. J. Electrochem. Sci. 2015;10:6754-6767.

22. Asaithambi P, Aziz ARA, Daud WMAW. Integrated ozone-electrocoagulation process for the removal of pollutant from industrial effluent: Optimization through response surface methodology. Chem. Eng. Process. 2016;105:92-102.

23. Behin J, Farhadian N, Ahmadi M, Parvizi M. Ozone assisted electrocoagulation in a rectangular internal-loop airlift reactor: Application to decolorization of acid dye. J. Water Process Eng. 2015;8:171-178.

24. Bernal-Martínez LA, Barrera-Díaz C, Natividad R, Rodrigo MA. Effect of the continuous and pulse in situ iron addition onto the performance of an integrated electrochemical-ozone reactor for wastewater treatment. Fuel 2013;110:133-140.

25. Bernal-Martínez LA, Barrera-Díaz C, Solís Morelos C, Natividad R. Synergy of electrochemical and ozonation processes in industrial wastewater treatment. Chem. Eng. J. 2010;165:71-77.

26. Khan NA, Khan SU, Ahmed S, et al. Recent trends in disposal and treatment technologies of emerging-pollutants-A critical review. TrAC, Trends Anal. Chem. 2019;115744.

27. Genç N, Durna E. Optimization of operational parameters by Taguchi design for imidacloprid oxidation by microwave-activated persulfate. Environ. Prog. Sustain. Energ. 2018;37:1632-1637.

28. Jayakumar E, Chittibabu S, Shanmugasundaram S, Tabil LG Synergetic effect of microwave heated alkali pre-treatment on densification of rice (Oryza sativa) husk biomass grinds. Energ. Sour. Part A. 2019;1660436.

29. APHA. Standard methods for the examination of water and wastewater: 21st ed. Washington, DC: American Public Health Association; 2015.

30. Ross PJ. Taguchi Techniques for Quality Engineering, Singapore: McGraw Hill Professional Editions, New York;1996. pp 329.
31. Kim S, Yim B, Park, Y. Application of Taguchi experimental design for the optimization of effective parameters on the rapeseed methyl ester production. Environ. Eng. Res. 2010;15: 129-134.

32. Brans JP, Vincke PH, Mareschal B. How to select and how to rank projects: the PROMETHEE method. Eur. J. Oper. Res. 1986;24:228-238.

33. Abdullah L, Chan W, Afshari AJ. Application of PROMETHEE method for green supplier selection: a comparative result based on preference functions. Ind. Eng. Int. 2019;15:271.

34. Gul M, Celik E, Taskin Gumus A, Guneri AF. A fuzzy logic based promethee method for material selection problems. Beni-Suef Univ. J. Basic Appl. Sci. 2018;7:68-79.

35. Tuzkaya G, Gülsün B, Kahraman C, Özgen D. An İntegrated fuzzy multi-criteria decision making methodology for material handling equipment selection problem and an application. Expert Syst. Appl. 2010;37:2853-2863.

36. Behzadian M, Kazemzadeh RB, Albadvi A, Aghdasi M. PROMETHEE: a comprehensive literature review on methodologies and applications. Eur. J. Oper. Res. 2010;200:198-215.

37. Şenkayas H, Hekimoğlu H. Application of PROMETHEE method for multiple criteria supplier selection problem. J. Product. Anal. 2013;2:63-80.

38. Li RJ. Fuzzy method in group decision making. Comput. Math Appl. 1999;38:91-101.

39. Elizabeth S, Sujatha L. Project scheduling method using triangular intuitionistic fuzzy numbers and triangular fuzzy numbers. Appl. Math. Sci. 2015;9:185-198.

40. Ernst M, Lurot F, Schrotter JC. Catalytic ozonation of refractory organic model compounds in aqueous solution by aluminum oxide. Appl. Catal. B. 2004;47:15-25.

41. Qi F, Chen Z, Xu B, et al. Influence of surface texture and acid-base properties on ozone decomposition catalyzed by aluminium (hydroxyl) oxides. Appl. Catal. B. 2008;84:684-690.

42. Hutson A, Ko S, Huling SG. Persulfate oxidation regeneration of granular activated carbon: Reversible impacts on sorption behavior. Chemosphere 2012;89:1218-1223.

43. Matzek LW, Carter KE. Activated persulfate for organic chemical degradation: A review. Chemosphere 2016;151:178-188.

44. Gholikandi GB, Zakizadeh N, Masihi H. Application of peroxymonosulfate-ozone advanced oxidation process for simultaneous waste-activated sludge stabilization and dewatering purposes: A comparative study. J. Environ. Manage. 2018;206: 523-531.

45. Yang Y, Guo H, Zhang Y, Deng Q, Zhang J. Degradation of bisphenol a using ozone/persulfate process: kinetics and mechanism. Water Air Soil Pollut. 2016;227:53.

46. Amr SSA, Aziz HA, Adlan MN, Bashir MJK. Pretreatment of stabilized leachate using ozone/persulfate oxidation process. Chem. Eng. J. 2013;221:492-499.

47. Orescanin V, Kollar R, Nad K. The application of the ozonation/electrocoagulation treatment process of the boat pressure washing wastewater. J. Environ. Sci. Health, Part A: Environ. Sci. Eng. 2011;46:1338-1345.

48. Gengec E, Kobya M, Demirbas E, Akyol A, Oktor K. Optimization of baker's yeast wastewater using response surface methodology by electrocoagulation. Desalination 2012;286:200-209. 
49. Asem M, Nawawi WMFW, Jimat DN. Evaluation of water absorption of polyvinyl alcohol-starch biocomposite reinforced with sugarcane bagasse nanofibre: optimization using two-level factorial design. IOP Conf. Ser.: Mater. Sci. Eng. 2018;368:012005.

50. Abdulredha MM, Hussain SA, Abdullah LC. Separation emulsion via non-ionic surfactant: an optimization. Processes 2019;7:382.

51. Gomes JAG, Daida P, Kesmez M, et al. Arsenic removal by electrocoagulation using combined $\mathrm{Al}-\mathrm{Fe}$ electrode system and characterization of products. J. Hazard. Mater. 2007;139:220-231.

52. Ji JF, Ge Y, Balsam W, Damuth JE, Chen J. Rapid identification of dolomite using a fourier transform infrared spectrophotometer (FTIR): a fast method for identifying Heinrich events in IODP Site U1308. Mar. Geol. 2009;258:60-68.

53. Kiefer J, Stärk A, Kiefer AL, Glade, H. Infrared Spectroscopic Analysis of the Inorganic Deposits from Water in Domestic and Technical Heat Exchangers. Energies 2018;11:798.

54. Durna E, Koz G, Genç N. Determination of the most suitable disposal option in the management of end of life tires in turkey by fuzzy PROMETHEE method. J. Polytechnic. 2020. (accepted; in press). 